\title{
Genetic variability among sorghum accessions for seed starch and stalk total sugar
}

\section{content}

\author{
Abe Shegro Gerrano ${ }^{1,{ }^{*}}$, Maryke Tine Labuschagne ${ }^{1}$, Angeline van Biljon ${ }^{1}$, Nemera Geleta Shargie $^{2}$
}

'University of the Free State - Dept. of Plant Sciences, PO Box 339, Bloemfontein - 9300 - South Africa. ${ }^{2}$ Agricultural Research Council/Grain Crops Institute, Private Bag X1251 - Potchefstroom 2520 - South Africa.

*Corresponding author <agerrano@arc.agric.za>

Edited by: Martin Boer

Received October 04, 2013

Accepted May 21, 2014

\begin{abstract}
Sorghum (Sorghum bicolor (L.) Moench) is a staple food grain in many semi-arid and tropical areas of the world, notably in sub-Saharan Africa because of its adaptation to harsh environments. Among important biochemical components for sorghum for processors are the levels of starch (amylose and amylopectin) and total sugar contents. The aim of this study was to determine the genetic variation for total starch in the seed, its components and total sugar in the stalks of the sorghum accessions from Ethiopia and South Africa. Samples of 22 sorghum accessions were evaluated. Significant variations were observed in total starch (31.01 to 64.88 $\%$ ), amylose (14.05 to $18.91 \%)$, the amylose/amylopectin ratio (0.31 to 0.73 ) and total stalk sugar content (9.36 to $16.84 \%$ ). Multivariate analysis showed a wide genetic variation within and among germplasm accessions which could be used in the selection of parental lines for the improvement of traits of interest through breeding. The variation found among the sorghum accessions shows that an improved total starch and starch components and stalk sugar contents can be achieved through crossing these selected genotypes.

Keywords: amylopectin, amylose, biochemical, protein, multivariate
\end{abstract}

\section{Introduction}

For millions of people in the developing countries, mainly in Africa, sorghum (Sorghum bicolor (L.) Moench) is an important staple food. Improvements in production, availability, storage, utilisation and consumption of sorghum will significantly contribute to these communities as a source of food security and nutrition (FAO, 1995). As a food crop, sorghum can provide a healthy diet for human nutrition (Mudjisihino and Damardjati, 1987). More than $35 \%$ of sorghum is grown directly for human consumption; the rest is used primarily for animal feed, alcohol production and industrial products (FAO, 1995; Awika and Rooney, 2004; Dicko et al., 2006; Mehmood et al., 2008). The crop can tolerate drought and hot climate, and can be successfully grown in all types of soils except water logged and saline soils. Selection of varieties meeting specific local food and industrial requirements is very important (Anglani, 1998).

Starch is the predominant storage carbohydrate in plants and the most important source of carbohydrate in the human diet where it occupies an important source of energy (Bednar et al., 2000). In sorghum grain, starch is the major proximate component (63 to $74 \%$ ) and the major energy supplier (Perez-Maldonado and Rodriguez, 2007). Starch granules consist of a linear polysaccharide called amylose (20-30 \% of starch) and a highly branched polysaccharide called amylopectin (70-80 \% of starch). The two starch components have different properties and are not suitable for the same applications (Zobel, 1988). The total starch and the relative proportion of

\$Present address: Agricultural Research Council - Vegetable and Ornamental Plant Institute, Private Bag X293 - Pretoria 0001 - South Africa. amylose and amylopectin vary considerably within plant species, plant organs, and depend on organ development and growth conditions.

Sorghum starch granules are surrounded by a protein matrix that can limit the access of enzymes (Oria et al., 2000; Benmoussa et al., 2006). Typical levels of amylose and amylopectin in cereal starches are 25-28 \% and $72-75 \%$, respectively, although for starches of some botanical sources, high amylose (up to $70 \%$ amylose) and waxy $(<1 \%$ amylose) genotypes also exist (Jane et al., 1999). Sorghum varieties containing 10 to $25 \%$ sugar in their stalks, near the time of grain maturity can be used to produce sugar or syrup (Hunter and Anderson, 1997). This adds another economic benefit to farmers and genotypes with both good grain yield and sugary stalks can be selected by breeders as dual purpose varieties. Hence, the objective of the study was to determine the starch contents, and its components in seed, as well as total sugar in stalks of sorghum accessions.

\section{Materials and Methods}

\section{Site and plant material}

The trials were conducted at Potchefstroom, South Africa (2674' $\mathrm{S} ; 27^{\circ} 8^{\prime} \mathrm{E}, 1,344 \mathrm{~m}$ above sea level and summer temperatures range between 22 and $34{ }^{\circ} \mathrm{C}$ with an average annual total rainfall of $619 \mathrm{~mm}$ during the 2009 and 2010 summer seasons. The sorghum accessions used for the determination of total starch and its components as well as stalk sugar content are listed in Table 1.

\section{Starch extraction}

Starch content was determined using a Total Starch Assay procedure [Amyloglucosidase/ $\alpha$-Amylase Method (Megazyme International Ireland Ltd, Bray, Ireland)]. 
Sorghum seeds were cleaned manually and ground. One hundred $\mathrm{mg}$ of each sorghum flour sample was weighed into test tubes. Each sample was wetted with $0.2 \mathrm{~mL}$ aqueous ethanol $(80 \% \mathrm{v} / \mathrm{v})$ to aid dispersion and mixed in a vortex mixer. Dimethyl sulphoxide (DMSO, $2 \mathrm{~mL}$ ) was added to each sample immediately after which they were vigorously stirred in a vortex mixer. The samples were incubated in a boiling water bath at $95{ }^{\circ} \mathrm{C}$ for $5 \mathrm{~min}$. Three $\mathrm{mL}$ of thermostable $\alpha$-amylase in 3-morpholinopropanesulfonic acid (MOPS) buffer was added to each sample and vigorously mixed using a vortex mixer. The samples were then incubated in a boiling water bath at $95^{\circ} \mathrm{C}$ for 6 min while stirring after 2 and 4 min using a vortex mixer.

Four $\mathrm{mL}$ sodium acetate buffer and $0.1 \mathrm{~mL}$ amyloglucosidase were added to each tube and vortexed. The samples were incubated in a water bath at $50{ }^{\circ} \mathrm{C}$ for 30 min followed by the addition of $0.1 \mathrm{~mL}$ distilled water. The samples were mixed thoroughly and centrifuged at $3000 \mathrm{rpm}$ for $10 \mathrm{~min}$. One $\mathrm{mL}$ aliquot from each tube was transferred into new tubes; this was done in duplicates. Nine $\mathrm{mL}$ distilled water were added to duplicates and the tubes were shaken.

Duplicate aliquots of $0.1 \mathrm{~mL}$ of diluted solution were transferred to the bottom of new glass test tubes and $3.0 \mathrm{~mL}$ glucose oxidase peroxidase 4-aminoantipyrine (GOPOD) reagent was added to each tube (including the glucose controls and reagent blanks) and incubated at $50{ }^{\circ} \mathrm{C}$ for $20 \mathrm{~min}$. The absorbance was read against the reagent blank at 510 $\mathrm{nm}$ for each sample, including the glucose control. The percentage total starch (dry weight basis) was calculated as follows:

$$
\begin{aligned}
\text { Starch } & =[\Delta \mathrm{A} \times \mathrm{F} \times 1000 \times 1 / 1000 \times 100 / \mathrm{W} \times 162 / 180] \\
& =\Delta \mathrm{A} \times \mathrm{F} / \mathrm{W} \times 90
\end{aligned}
$$

where $\Delta \mathrm{A}=$ Absorbance (reaction) read against the reagent blank; $F=100$ ( $\mu$ g of glucose)/Absorbance of $100 \mu \mathrm{g}$ glucose; $1000=$ Volume correction $(0.1 \mathrm{~mL}$ taken from $100 \mathrm{~mL}) ; 1 / 1000=$ Conversion from micrograms to milligrams; $100 / \mathrm{W}=$ Factor to express "starch" as a percentage of flour weight; $\mathrm{W}=$ weight in milligrams ("as is" basis) of the flour analysed; and 162/180 = Adjustment from free glucose to anhydro glucose (as occurs in starch)

\section{Amylose/amylopectin content determination}

Amylose content of the starch was estimated by the iodine binding method (Cruz and Khush, 2000). One hundred $\mathrm{mg}$ of sorghum flour sample was weighed. The samples were wetted with addition of $1 \mathrm{~mL} 95 \%$ (v/v) ethanol followed by $9 \mathrm{~mL} 1 \mathrm{M} \mathrm{NaOH}$ to aid dispersion and stirred using a vortex mixer. The samples were placed in a boiling water bath for $15 \mathrm{~min}$ and stirred using a vortex mixer every $5 \mathrm{~min}$. The samples were cooled at room temperature for $1 \mathrm{~h}$ and then centrifuged at 3,000 rpm for $5 \mathrm{~min}$. Duplicate $0.1 \mathrm{~mL}$ aliquots of the solution were transferred into clean test tubes and
$0.1 \mathrm{~mL} 1 \mathrm{M}$ acetic acid was added to each test tube followed by addition of $0.2 \mathrm{~mL}$ iodine solution and $9.6 \mathrm{~mL}$ distilled water. The contents were vortexed and left to stand for $20 \mathrm{~min}$. The absorbance was read against the reagent blank at $620 \mathrm{~nm}$ for each sample. The amylose percentage was calculated using the formula:

Amylose $\%=\{[$ Concentration $(\mathrm{mg} / \mathrm{mL}) \times 1000] /$ Mass of the sample $(\mathrm{mg})\} \times 100$

Amylopectin was calculated as 100 - amylose \%.

\section{Sugar content determination}

The total sugar content in stalks was estimated at physiological maturity as the Brix \% using a hand held refractometer. The samples were taken from the third internode from the base of the plant for uniformity of sampling. The sap was squeezed and extracted from the cut stalks with pliers and placed on a hand held refractometer, after which readings were taken.

\section{Statistical analysis}

Starch data and its components were subjected to analysis of variance (ANOVA) for the 2009 and 2010 cropping seasons. A combined ANOVA over two years was also performed for each parameter. Furthermore, data was subjected to multivariate analysis using the Number Cruncher Statistical System (NCSS, 2004). A dendrogram and principal component analysis (PCA) was generated to show the genetic relationships among the accessions using NCSS. The measure of dissimilarity was the Euclidean distance and the hierarchical agglomerative clustering method using the Unweighted Pair-Group Method with Arithmetic Mean (UPGMA) was used to examine the grouping of accessions. Euclidean measure of genetic distance was used for estimating genetic distance (GD) among accessions (Mohammadi and Prasanna, 2003).

\section{Results and Discussion}

\section{Univariate statistics}

The ANOVA revealed that there were highly significant $(p \leq 0.01)$ differences (Table 1) among the accessions for all measured parameters indicating that there was a wide range of genetic variability among them. Variation was also observed in the mean values for the same parameters for the accessions grown in the 2009 and 2010 cropping seasons. The accessions from the 2009 cropping season had an almost $10 \%$ lower total starch content than in 2010. Amylopectin and the amylose/ amylopectin ratio were similar for the two seasons. Stalk sugar content was slightly higher in 2010. The lower starch values in 2009 might have been due to a much lower rainfall in 2009 compared to 2010 (Appendix I), though trial was supplemented by irrigation water. Temperatures in the first three months after planting were 1-2 ${ }^{\circ} \mathrm{C}$ warmer in 2009 than in 2010, but the following three months (Feb to Apr) were $1-2^{\circ} \mathrm{C}$ cooler than in 2010. 
Table 1 - Means, mean squares, least significant differences and coefficient of variation for total starch, and its components and stalk sugar in sorghum accessions for the 2009 and 2010 cropping seasons.

\begin{tabular}{|c|c|c|c|c|c|c|c|c|c|c|c|c|}
\hline \multirow{2}{*}{ No. } & \multirow{2}{*}{ Accessions } & \multirow{2}{*}{ Origin } & \multicolumn{2}{|c|}{ Year 2009} & \multicolumn{8}{|c|}{ Year 2010} \\
\hline & & & Starch & ${ }^{\mathrm{a} A m}$ & ${ }^{\mathrm{a} A m p}$ & Am:Amp ${ }^{b}$ & Total sugar & Starch & $\mathrm{Am}$ & Amp & $A m: A m p^{b}$ & Total sugar \\
\hline & & & & $-\%$ & & & & & & & & $\%$ \\
\hline 1 & 216737 & Ethiopia & 47.86 & 14.53 & 83.47 & 0.17 & 16.33 & 57.64 & 13.57 & 86.43 & 0.16 & 17.02 \\
\hline 2 & 216743 & Ethiopia & 66.52 & 13.05 & 86.95 & 0.15 & 13.70 & 57.53 & 15.61 & 84.39 & 0.19 & 13.42 \\
\hline 3 & Birmash & Ethiopia & 31.01 & 14.90 & 85.10 & 0.18 & 13.85 & 57.77 & 16.02 & 83.98 & 0.19 & 9.68 \\
\hline 4 & Gambella-1107 & Ethiopia & 55.02 & 16.31 & 83.69 & 0.19 & 3.69 & 62.96 & 16.00 & 84.00 & 0.19 & 11.33 \\
\hline 5 & IS9302 & ICRISAT & 49.34 & 18.10 & 81.90 & 0.22 & 10.34 & 55.86 & 18.80 & 81.20 & 0.23 & 14.33 \\
\hline 6 & Baji & Ethiopia & 54.32 & 18.10 & 81.90 & 0.22 & 16.19 & 47.31 & 18.23 & 81.77 & 0.22 & 15.57 \\
\hline 7 & 97MW6129 & Ethiopia & 51.94 & 19.91 & 80.09 & 0.25 & 11.23 & 59.22 & 16.82 & 83.18 & 0.20 & 14.61 \\
\hline 8 & 97MW6127 & Ethiopia & 36.78 & 18.80 & 81.20 & 0.23 & 11.53 & 53.96 & 15.82 & 84.18 & 0.19 & 14.79 \\
\hline 9 & NO253 & ICRISAT & 49.95 & 12.98 & 87.02 & 0.15 & 14.35 & 60.25 & 18.02 & 81.98 & 0.22 & 11.04 \\
\hline 10 & PI308453 & $\begin{array}{l}\text { Purdue } \\
\text { University }\end{array}$ & 49.96 & 15.34 & 84.66 & 0.18 & 14.60 & 59.90 & 17.53 & 82.47 & 0.21 & 8.27 \\
\hline 11 & 97MW6113 & Ethiopia & 61.54 & 15.19 & 84.81 & 0.18 & 16.85 & 74.57 & 18.22 & 81.78 & 0.22 & 10.40 \\
\hline 12 & Macia-SA & SA & 60.86 & 17.53 & 82.47 & 0.21 & 12.59 & 57.86 & 15.23 & 84.77 & 0.18 & 14.36 \\
\hline 13 & M48 & South Africa & 64.88 & 17.70 & 82.30 & 0.22 & 6.17 & 62.77 & 17.07 & 82.93 & 0.21 & 12.56 \\
\hline 14 & M141 & South Africa & 56.34 & 17.69 & 82.31 & 0.21 & 14.62 & 56.80 & 15.23 & 84.77 & 0.18 & 19.07 \\
\hline 15 & M81 & South Africa & 34.23 & 16.59 & 83.41 & 0.20 & 7.99 & 64.44 & 15.37 & 84.63 & 0.18 & 12.83 \\
\hline 16 & M105 & South Africa & 39.78 & 18.09 & 81.91 & 0.22 & 13.94 & 63.33 & 14.71 & 85.29 & 0.17 & 13.52 \\
\hline 17 & M26 & South Africa & 52.88 & 20.47 & 79.53 & 0.26 & 15.93 & 54.83 & 15.77 & 84.23 & 0.19 & 14.25 \\
\hline 18 & M101 & South Africa & 47.14 & 17.53 & 82.47 & 0.21 & 16.64 & 63.90 & 20.29 & 79.71 & 0.25 & 16.57 \\
\hline 19 & M163 & South Africa & 51.75 & 13.31 & 86.69 & 0.15 & 10.55 & 59.43 & 16.34 & 83.66 & 0.19 & 15.15 \\
\hline 20 & Masekaswere & South Africa & 37.60 & 17.85 & 82.15 & 0.22 & 18.58 & 57.21 & 16.69 & 83.31 & 0.20 & 14.95 \\
\hline 21 & Mamolokwane & South Africa & 35.56 & 17.97 & 82.03 & 0.22 & 15.65 & 63.99 & 14.60 & 85.40 & 0.17 & 14.37 \\
\hline \multirow[t]{5}{*}{22} & M153 & South Africa & 54.47 & 14.12 & 85.88 & 0.16 & 13.67 & 64.39 & 15.58 & 84.42 & 0.18 & 20.78 \\
\hline & & Mean squares & $303.377^{* *}$ & $14.081^{* *}$ & $14.081^{* *}$ & $0.003^{* *}$ & $40.324^{* *}$ & $84.391^{* *}$ & $7.486^{* *}$ & $7.486^{* *}$ & $0.002^{* *}$ & $25.411^{\text {* * }}$ \\
\hline & & LSD & 3.07 & 1.21 & 1.21 & 0.01 & 1.45 & 3.43 & 1.50 & 1.50 & 0.02 & 1.25 \\
\hline & & CV \% & 3.76 & 4.42 & 0.88 & 5.64 & 6.72 & 3.48 & 5.56 & 1.09 & 7.07 & 5.44 \\
\hline & & Mean & 49.53 & 16.64 & 83.36 & 0.20 & 13.13 & 59.81 & 16.43 & 83.57 & 0.20 & 14.04 \\
\hline
\end{tabular}

This could have influenced the values measured. Ellies et al. (1998) reported that starch content is influenced by the genetic and environmental conditions.

A high level of significant variation was seen for all variables in the combined ANOVA (Table 2). Total starch content ranged from 44.39 to $68.05 \%$ in the present study. Among all accessions, the highest value was recorded for accession 97MW6113 (from Ethiopia); while the lowest was found for Birmash (also from Ethiopia). Intermediate starch content was obtained for accessions NO253 and PI308453. Wester et al. (1992) reported similar starch content for 48 commercial grain sorghum hybrids.

Amylose content is important for food processing in the industry and for quality. From all accessions, the highest amylose content was recorded in accession M101 (18.91 \%, from South Africa); while the lowest was found in accessions 216737 (14.05\%) and 216743 $(14.33 \%)$, both from Ethiopia. These values were lower than those reported by the FAO (1995), Beta et al. (2000), Beta and Corke (2001), Geleta et al. (2005), Salinas et al. (2006), Chanapamokkhot and Thongngam (2007) and Boudries et al. (2009) but within the range of what McDonouch et al. (1998) reported (2.0 to $28 \%$ ).
Benmoussa et al. (2006) found that the amylose content ranged between 19.2 to $22.4 \%$. Furthermore, Beta and Corke (2001) reported amylose content ranging from 20.9 to $30.2 \%$, while Salinas et al. (2006) reported amylose content ranging from 25.28 to $28.26 \%$. Grains with low amylose contents (1-2 \%) are termed "waxy", and are associated with homogenous recessive genes $(w x w x w x)$. Non-waxy grains are those with normal levels of amylose (23-28\%). According to Ring et al. (1982), accessions grouped as heterowaxy contain lower amylose content than non-waxy grains, which contains 24 to $30 \%$ amylose. Heterowaxy grains have lower amylose contents than normal grains $(20 \%)$ but display many of the physical attributes of non-waxy grains (McDonough et al., 1998). Both genetic and environmental factors affect the amylose content of sorghum (Beta and Corke (2001). Wang et al. (2008) reported that waxy and heterowaxy sorghum varieties have higher ethanol yields than nonwaxy varieties, at the same starch level.

The amylose content has been reported to vary with the botanical source of the starch and is affected by the climatic and soil conditions during grain development (Yano et al., 1985; Boudries et al., 2009). Environmental 
Table 2 - Means, mean squares, least significant difference and coefficient of variation for the starch and its components averaged over two

\begin{tabular}{|c|c|c|c|c|c|c|}
\hline No. & Accessions & Starch & ${ }^{a}$ Amylose & ${ }^{a}$ Amylopectin & Am:Amp ${ }^{b}$ & Total sugar \\
\hline & & 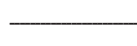 & $\%$ & $\longrightarrow$ & & $\%$ \\
\hline 1 & 216737 & 52.75 & 14.05 & 85.95 & 0.16 & 16.68 \\
\hline 2 & 216743 & 62.02 & 14.33 & 85.67 & 0.17 & 13.56 \\
\hline 3 & Birmash & 44.39 & 15.46 & 84.54 & 0.18 & 11.76 \\
\hline 4 & Gambella-1107 & 58.99 & 16.16 & 83.85 & 0.19 & 7.51 \\
\hline 5 & IS9302 & 52.60 & 18.45 & 81.55 & 0.23 & 12.33 \\
\hline 6 & Baji & 50.81 & 18.16 & 81.84 & 0.22 & 15.88 \\
\hline 7 & 97MW6129 & 55.58 & 18.36 & 81.64 & 0.23 & 12.92 \\
\hline 8 & 97MW6127 & 45.37 & 17.31 & 82.69 & 0.21 & 13.16 \\
\hline 9 & N0253 & 55.10 & 15.50 & 84.50 & 0.19 & 12.70 \\
\hline 10 & PI308453 & 54.93 & 16.43 & 83.57 & 0.20 & 11.44 \\
\hline 11 & 97MW6113 & 68.05 & 16.71 & 83.29 & 0.20 & 13.63 \\
\hline 12 & Macia-SA & 59.36 & 16.38 & 83.62 & 0.19 & 13.48 \\
\hline 13 & M48 & 63.82 & 17.38 & 82.62 & 0.21 & 9.36 \\
\hline 14 & M141 & 56.57 & 16.46 & 83.54 & 0.20 & 16.84 \\
\hline 15 & M81 & 49.33 & 15.98 & 84.02 & 0.19 & 10.41 \\
\hline 16 & M105 & 51.55 & 16.40 & 83.60 & 0.20 & 13.73 \\
\hline 17 & M26 & 53.86 & 18.12 & 81.88 & 0.22 & 15.09 \\
\hline 18 & M101 & 55.52 & 18.91 & 81.09 & 0.23 & 16.60 \\
\hline 19 & M163 & 55.59 & 14.83 & 85.17 & 0.17 & 12.85 \\
\hline 20 & Masekaswere & 47.40 & 17.27 & 82.73 & 0.21 & 16.76 \\
\hline 21 & Mamolokwane & 49.77 & 16.28 & 83.72 & 0.20 & 15.01 \\
\hline \multirow{5}{*}{22} & M153 & 59.43 & 14.85 & 85.15 & 0.17 & 17.22 \\
\hline & Mean squares & $182.851^{* *}$ & $10.329^{* *}$ & 10.329 * * & $0.002^{* *}$ & $26.156^{* *}$ \\
\hline & LSD & 2.26 & 0.95 & 0.95 & 0.01 & 0.94 \\
\hline & CV \% & 3.61 & 5.02 & 0.99 & 6.38 & 6.07 \\
\hline & Mean & 54.67 & 16.54 & 83.47 & 0.20 & 13.59 \\
\hline
\end{tabular}

${ }^{\star *} p \leq 0.01$; a Mean percent values of amylose and amylopectin, respectively; ${ }^{\mathrm{b} A m: A m p}=$ amylose/amylopectin ratio.

and genetic factors determine amylose levels in sorghum (Taylor et al., 1997). Beta and Corke (2001) reported that sorghum genotype and growing environment affect the amylose content. The amylose content of rice was also reported to be affected by both environment and genotype (Juliano et al., 1964). It is possible to increase the amylose content of seed through breeding, as a large variation is observed in grain sorghum. In this study there was a limited variation in amylopectin content, $4.86 \%$ difference between the highest and lowest values. The average values for Ethiopian and South African material were very similar (16.45 and $16.62 \%$, data not shown).

The amylose/amylopectin ratio is an important characteristic of starch that governs much of starch functionality. The ratio of amylose to amylopectin varied from 0.16 to 0.23 . The highest ratio was observed for accessions IS9302, 97MW6127 and M101. The values obtained were lower than those reported by Arora and Luthra (1972) and Boudries et al. (2009).

The studies by Arora and Luthra (1972), Sabramanian et al. (1987), FAO (1995), Ali et al. (2008) and Audilakshmi et al. (2010) were conducted earlier to estimate total stalk sugars in various sorghum accessions. In the current study the content of total stalk sugar ranged from 7.51 to $17.22 \%$ among the accessions. The highest total sugar content of all accessions measured was in M153 (17.22 \%) and M141 (16.84); while the lowest total sugar content was scored for Gambella-1107. Accessions M153 and M141 may have good genetic potential for future use as dual purpose sorghum types for sugar and grain production. Sweet sorghum fodders may contain up to $21 \%$ total sugars (Coleman, 1970).

Hunter and Anderson (1997) reported that sorghum varieties which contained 10 to $25 \%$ sugar in their stalks near the time of grain maturity can be used to produce sorghum sugar. Therefore, selection and breeding accessions of higher grain yield as well as higher sugar content is important to future sorghum breeding. Rajvanshi and Nimbkar (2008) suggested that the production of grain and sugar from the same plant are very important attributes since food and fuel can be produced simultaneously from the same piece of land. The sugar content of the South African material was on average $1.43 \%$ higher than that of the Ethiopian material, but the potential is there to select high sugar yielding cultivars from both sets of materials. These values were higher than the values reported by Ragaee et al. (2006) and Boudries et al. (2009) but lower than values reported by Owuama (1997), Lee et al. (2002), Osman (2004), Salinas et al. (2006) and Sang et al. (2008). Wang et al. (2008) 
found that starch content in sorghum genotypes ranged between 64 and $74 \%$ of grain dry weight. The average values for Ethiopian and South African materials were very similar (54.6 and 54.75, data not shown).

\section{Principal component analysis}

The first three eigenvectors cumulatively explained about $99.62 \%$ of the total variation among the accessions (Table 3). The first principal component (PC) alone explained $60.06 \%$ of the total variation, mainly due to variation in amylose, amylopectin and the amylose to amylopectin ratio with the same weight but in the opposite direction for amylopectin. A variable which contributed more to the second PC accounted for 22.56 $\%$ of the total variation and was dominated by traits such as starch and total sugar contents. Similarly, the third PC with $17.00 \%$ of the variation was composed of starch and total sugar both with the negative weight with the highest negative loading contributed by total starch.

The eigenvectors of PC3 showed large negative loadings for the starch content. All characters in this PC contributed negatively except amylopectin though the contribution of the variation is very little. The first and the second PCs explained the most variation among the sorghum accessions, revealing a high degree of association among the starch components studied. The existence of a wider genetic variability in starch and its compositions was further explained and confirmed by the PCA biplot (Figure 1). The PCA grouped the accessions into different clusters over the four quadrants based on their relationship to starch and its component traits.

The accessions were scattered in all quadrants which showed that there was high genetic variability among them. Accessions close to each other in the principal component axes had relatively similar genetic relationships in these traits. Accessions 216737, Masekaswere, M48 and Gambella-1107 were extreme accessions from the origin indicating that these accessions have a peculiar gene/allele among the accessions studied. These accessions would be selected for hybridization/crossing for the traits of interest to develop new cultivar. Accessions 216737 and Masekaswere had showed similar relationships in the second PC with accessions M48 and Gambella-1107. This result was

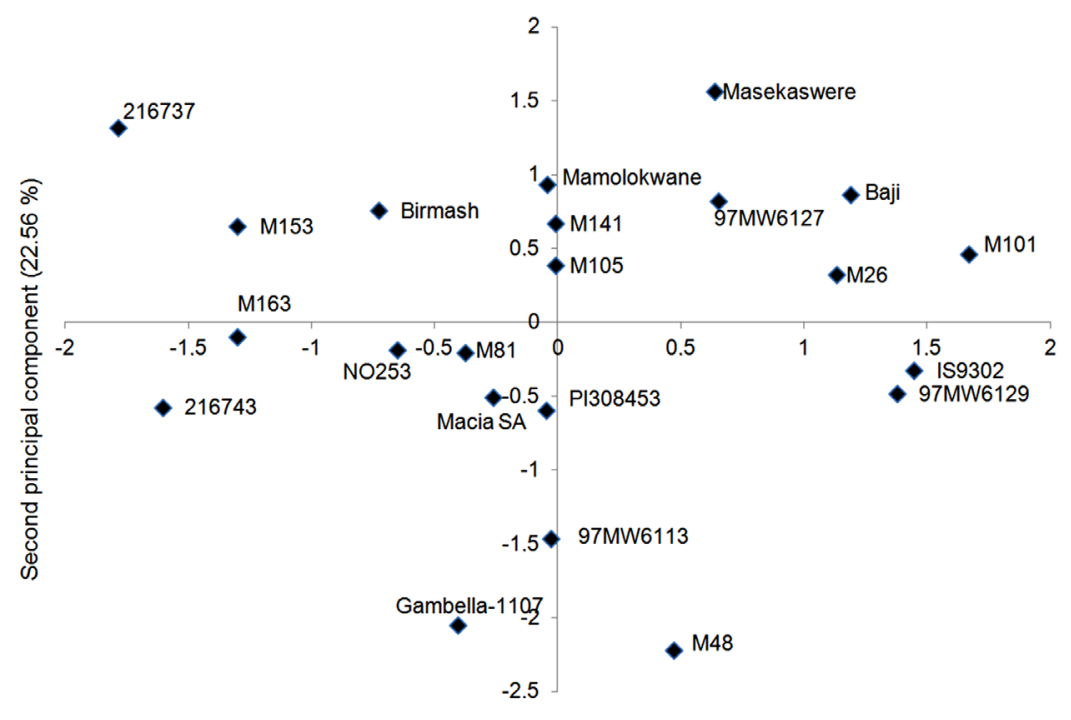

First principal component $(60.06 \%)$

Figure 1 - Principal component score plot of PC1 and PC2 describing the overall variation among sorghum accessions estimated using the data set of starch and its components.

Table 3 - Principal component analysis of starch and its components in 22 sorghum accessions showing eigenvectors, eigenvalues, individual and cumulative percentage of variation explained by the first three PC axes.

\begin{tabular}{|c|c|c|c|c|c|c|c|c|}
\hline \multirow{2}{*}{ PC } & \multirow{2}{*}{ Eigenvalue } & \multicolumn{2}{|c|}{ Total variance } & \multicolumn{5}{|c|}{ Eigenvectors } \\
\hline & & Individual & Cumulative & Starch & Amylose & Amylopectin & Am:Amp & Total sugar \\
\hline & & & & $-\%$ & & & & \\
\hline 1 & 3.00 & 60.06 & 60.06 & -0.10 & 0.57 & -0.57 & 0.57 & 0.03 \\
\hline 2 & 1.13 & 22.56 & 82.62 & -0.68 & -0.06 & 0.06 & -0.05 & 0.73 \\
\hline 3 & 0.85 & 17.00 & 99.62 & -0.73 & -0.04 & 0.04 & -0.02 & -0.68 \\
\hline
\end{tabular}

Am:Amp = amylose to amylopectin ratio. 
similar to what Shegro et al. (2013) found in 31 sorghum landrace accessions in Ethiopia.

\section{Genetic distance and cluster analysis}

Genetic distances from 0.60 to 2.17 were observed in the pair-wise combinations, indicating that the accessions were genetically diverse for the starch and starch components (Table 4). The minimum genetic distance of 0.60 was recorded between accessions Mamolokwane and M105 (South Africa). On the contrary, the highest genetic distance of 2.17 was recorded between accession 216737 and M101 (Ethiopia and South Africa, respectively) and the rest of the accessions, indicating that there was high genetic variability between the accessions.

The average genetic distances between the accessions from Ethiopia (1.30) and that of South Africa (1.16) were relatively divergent. Within the Ethiopian material there were 5 genetic distance values lower than 0.85 indicating some relatedness within the accessions, with an average distance of 1.16 . In the South African sorghum accessions 11 genetic distance values were lower than 0.87 . The accessions with the wider genetic distances between them can be included in sorghum improvement programs in both countries, Ethiopia and South Africa (Shegro et al., 2013).

Segmentation analysis for starch and its components showed a clear separation between the accessions (Figure 2). Furthermore, Table 5 showed differences among clusters of accessions by summarising cluster means for the variables recorded. Based on these variables, the accessions were clustered into different clusters. The dendrogram clustered the sorghum accessions into three main groups according to their genetic distance values. The first main cluster was produced at a genetic distance of 0.99 and included the accessions Masekaswere, M101, M26, 97MW6127, Baji, 97MW6129 and IS9302 (materials from South Africa, Ethiopia and ICRISAT).

Accession M101 was separated within the cluster indicating that it had some differences in the variables (Figure 2). Cluster I was grouped based on the lowest starch content, highest contents of amylose and amylose to amylopectin ratio. The second main cluster was

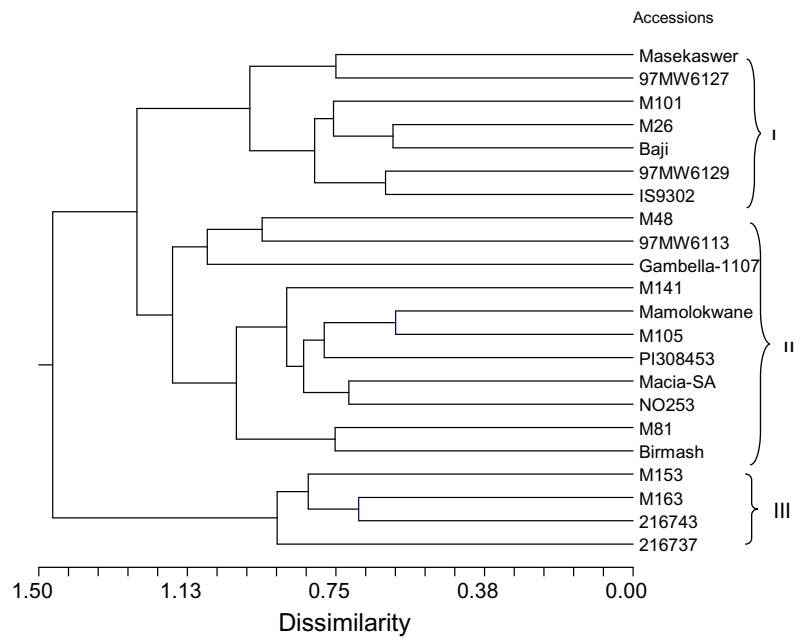

Figure 2 - Dendrogram of 22 sorghum accessions showed by UPGMA cluster analysis based on the data sets of starch and its components.

Table 4 - Estimates of genetic distance based on starch and its components for all pair-wise comparisons of 22 sorghum accessions.

\begin{tabular}{|c|c|c|c|c|c|c|c|c|c|c|c|c|c|c|c|c|c|c|c|c|c|c|}
\hline No. & Accessions & 1 & 2 & 3 & 4 & 5 & 6 & 7 & 8 & 9 & 10 & 11 & 12 & 13 & 14 & 15 & 16 & 17 & 18 & 19 & 20 & 21 \\
\hline 1 & 216737 & 1.00 & & & & & & & & & & & & & & & & & & & & \\
\hline 2 & 216743 & 0.95 & 1.00 & & & & & & & & & & & & & & & & & & & \\
\hline 3 & Birmash & 1.20 & 1.32 & 1.00 & & & & & & & & & & & & & & & & & & \\
\hline 4 & Gambella-1107 & 1.65 & 1.26 & 1.26 & 1.00 & & & & & & & & & & & & & & & & & \\
\hline 5 & IS9302 & 2.14 & 1.99 & 1.60 & 1.47 & 1.00 & & & & & & & & & & & & & & & & \\
\hline 6 & Baji & 1.89 & 1.87 & 1.52 & 1.64 & 0.84 & 1.00 & & & & & & & & & & & & & & & \\
\hline 7 & 97MW6129 & 2.09 & 1.89 & 1.66 & 1.44 & 0.62 & 0.84 & 1.00 & & & & & & & & & & & & & & \\
\hline 8 & 97MW6127 & 1.70 & 1.73 & 1.11 & 1.41 & 0.93 & 0.85 & 1.02 & 1.00 & & & & & & & & & & & & & \\
\hline 9 & N0253 & 1.11 & 0.93 & 0.93 & 0.94 & 1.43 & 1.36 & 1.38 & 1.15 & 1.00 & & & & & & & & & & & & \\
\hline 10 & PI308453 & 1.46 & 1.24 & 1.04 & 0.90 & 1.08 & 1.14 & 1.07 & 0.95 & 0.78 & 1.00 & & & & & & & & & & & \\
\hline 11 & 97MW6113 & 1.62 & 1.23 & 1.62 & 1.19 & 1.32 & 1.30 & 1.16 & 1.43 & 1.08 & 0.97 & 1.00 & & & & & & & & & & \\
\hline 12 & Macia-SA & 1.29 & 1.02 & 1.21 & 0.98 & 1.29 & 1.21 & 1.19 & 1.18 & 0.72 & 0.79 & 0.80 & 1.00 & & & & & & & & & \\
\hline 13 & M48 & 1.98 & 1.56 & 1.62 & 0.96 & 1.10 & 1.35 & 1.01 & 1.32 & 1.21 & 0.94 & 0.94 & 1.02 & 1.00 & & & & & & & & \\
\hline 14 & M141 & 1.33 & 1.25 & 1.36 & 1.42 & 1.27 & 1.01 & 1.16 & 1.12 & 0.99 & 0.97 & 0.90 & 0.82 & 1.29 & 1.00 & & & & & & & \\
\hline 15 & M81 & 1.35 & 1.28 & 0.75 & 0.93 & 1.35 & 1.37 & 1.39 & 1.00 & 0.75 & 0.80 & 1.37 & 0.98 & 1.28 & 1.25 & 1.00 & & & & & & \\
\hline 16 & M105 & 1.30 & 1.27 & 0.98 & 1.19 & 1.13 & 0.97 & 1.11 & 0.83 & 0.81 & 0.72 & 1.07 & 0.83 & 1.22 & 0.78 & 0.87 & 1.00 & & & & & \\
\hline 17 & M26 & 1.86 & 1.77 & 1.52 & 1.51 & 0.80 & 0.61 & 0.75 & 0.90 & 1.28 & 1.05 & 1.14 & 1.10 & 1.19 & 0.94 & 1.33 & 0.95 & 1.00 & & & & \\
\hline 18 & M101 & 2.17 & 2.06 & 1.87 & 1.80 & 0.84 & 0.77 & 0.76 & 1.16 & 1.60 & 1.35 & 1.30 & 1.36 & 1.35 & 1.15 & 1.67 & 1.25 & 0.74 & 1.00 & & & \\
\hline 19 & M163 & 0.90 & 0.69 & 1.00 & 1.11 & 1.79 & 1.69 & 1.74 & 1.47 & 0.77 & 1.05 & 1.27 & 0.94 & 1.48 & 1.19 & 0.99 & 1.07 & 1.62 & 1.94 & 1.00 & & \\
\hline 20 & Masekaswere & 1.59 & 1.70 & 1.28 & 1.64 & 1.08 & 0.76 & 1.10 & 0.75 & 1.22 & 1.12 & 1.38 & 1.17 & 1.49 & 0.93 & 1.23 & 0.84 & 0.84 & 1.04 & 1.50 & 1.00 & \\
\hline 21 & Mamolokwane & 1.24 & 1.30 & 0.96 & 1.32 & 1.22 & 1.01 & 1.21 & 0.86 & 0.86 & 0.84 & 1.19 & 0.92 & 1.38 & 0.80 & 0.91 & 0.60 & 1.01 & 1.31 & 1.09 & 0.81 & 1.00 \\
\hline 22 & M153 & 0.85 & 0.77 & 1.39 & 1.53 & 1.94 & 1.69 & 1.83 & 1.65 & 1.04 & 1.33 & 1.23 & 1.02 & 1.70 & 1.04 & 1.40 & 1.20 & 1.62 & 1.87 & 0.87 & 1.48 & 1.18 \\
\hline
\end{tabular}


Table 5 - Cluster means of starch and its components for the sorghum accessions based on the data set.

\begin{tabular}{lccccc}
\hline Clusters & Starch & Amylose & Amylopectin & Am:Amp & Total sugar \\
\cline { 2 - 4 } & & & & \\
I I & 51.59 & 18.08 & 81.92 & 0.22 & 14.68 \\
II & 55.62 & 16.29 & 83.72 & 0.19 & 12.35 \\
III & 57.45 & 14.52 & 85.49 & 0.17 & 15.08 \\
\hline
\end{tabular}

Am:Amp $=$ amylose to amylopectin ratio.

also created at a genetic distance of 1.16. This cluster consisted of 11 accessions both from Ethiopia and South Africa with average contents of starch, amylose, amylopectin and amylose to amylopectin ratio. The lowest concentration of sugar was recorded in this group. This cluster was sub-divided into two clusters at a genetic distance value of 1.41 containing accessions M81 and Birmash as well as accessions M141, Mamolokwane, M105, PI308453, Macia-SA and NO253.

The third cluster consisted of four accessions: two from South Africa (accessions M153 and M163) and two from Ethiopia (accessions 216743 and 216737) and was generated at a genetic distance of 0.85 . This cluster grouped the accessions with the highest contents of starch, amylopectin and total sugar with the lowest content of amylose and amylose to amylopectin ratio. It was observed that the accessions showed the highest genetic dissimilarity and were explained by a wide genetic variability among them using univariate and multivariate analysis.

Although PCA and cluster analysis grouped the sorghum accessions with greater biochemical similarity, all the accessions from the same region or origin were not necessarily grouped together. Grain starch and stalk sugar contents alone did not exhibit a high level of variation among the accessions from the two geographical regions, hence simultaneous studies for both morphoagronomic and biochemical analyses are suggested.

\section{Conclusions}

A very high variation for total starch was observed among the sorghum accessions, which will certainly allow selection for specific applications of cultivars, for example, for bio-fuel. The range of amylose content was smaller, but some variation was observed. There was quite a large variation in the stalk sugar content, which suggests very good selection potential for dual purpose cultivars, where sorghum grain and sugar can be produced by the same plants.

\section{Acknowledgements}

The first author would like to acknowledge the World Bank through the Ministry of Agriculture and Rural Development, Benishangul-Gumuz Regional State of Ethiopia for the financial support and the Institute of Biodiversity Conservation/Ethiopia and Agricultural
Research Council-Grain Crops Institute/South Africa for providing the sorghum germplasm for the study.

\section{References}

Ali, M.L.; Rajewski, J.F.; Baenziger, P.S.; Gill, K.S.; Eskridge, K.M.; Dweikat, I. 2008. Assessment of genetic diversity and relationship among a collection of US sweet sorghum germplasm by SSR markers. Molecular Breeding 21: 497-509.

Anglani, C. 1998. Sorghum for human food: a review. Plant Foods for Human Nutrition 52: 8589.

Arora, S.K.; Luthra, Y.P. 1972. Variability of starch and sugar contents in the grains of sorghum forages and its correlation with tannin and mineral matter content. Starch 2: 51-53.

Audilakshmi, S.; Mall, A.K.; Swarnalatha, M.; Seetharama, N. 2010. Inheritance of sugar concentration in stalk (brix), sucrose content, stalk and juice yield in sorghum. Biomass and Bioenergy 34: 813-820.

Awika, J.M.; Rooney, L.W. 2004. Sorghum phytochemicals and their potential aspects on human health. Phytochemistry 65: 1199-1221.

Bednar, G.E.; Patil, A.R.; Murray, S.M.; Grieshop, C.M.; Merchen, N.R.; Fahey, G.C. 2000. Starch and fiber fractions in selected food and feed ingredients affect their small intestinal digestibility and fermentability and their large bowel fermentability in vitro in a Canine Model. Journal of Nutrition 131: 276-286.

Benmoussa, M.; Suhendra, B.; Aboubacar, A.; Hamaker, B.R. 2006. Distinctive sorghum starch granule morphologies appear to improve raw starch digestibility. Starch 58: 92-99.

Beta, T.; Corke, H.; Rooney, L.W.; Taylor, J.R.N. 2000. Starch properties as affected by sorghum grain chemistry. Journal of the Science of Food and Agriculture 81: 245-251.

Beta, T.; Corke, H. 2001. Genetic and environmental variation in sorghum starch properties. Cereal Science 34: 261-268.

Boudries, N.; Belhaneche, N.; Nadjemi, B.; Deroanne, C.; Mathlouthi, M.; Roger, B.; Sindic, M. 2009. Physicochemical and functional properties of starches from sorghum cultivated in the Sahara of Algeria. Carbohydrate Polymers 78: 475-480.

Chanapamokkhot, H.; Thongngam, M. 2007. The chemical and physico-chemical properties of sorghum starch and flour. Kasetsart Journal: Natural Science 41: 343-349.

Coleman, O.H. 1970. Syrup and sugar from sweet sorghum. p. 416. In: Wall, J.S.; Ross, W.M., eds. Sorghum production and utilization. AVI, Westport, CT, USA.

Cruz, N.D.; Khush, G.S. 2000. Rice grain quality evaluation procedures. In: Singh, R.K.; Singh, U.S.; Khush, G.S., eds. Aromatic rice. Science Publishers, New Delhi, India.

Dicko, M.H.; Gruppen, H.; Traore, A.S.; Alphons, G.J.; Voragen, A.G.J.; Berkel, W.J.H. van. 2006. Sorghum grain as human food in Africa: Relevance of content of starch and amylase activities. African Journal of Biotechnology 5: 384-395.

Ellies, R.P.; Cochrane, M.P.; Dale, M.F.; Duffus, C.M.; Lynn, A.; Morrison, I.N.; Prentices, R.D.; Swantston, J.S.; Tiller, S.A. 1998. Starch production and industrial use. Journal of Science and Agriculture 77: 289-311.

Food and Agricultural Organization [FAO]. 1995. Sorghum and Millets in Human Nutrition. FAO, Rome, Italy. (FAO and Nutrition Series, 27). 
Geleta, N.; Labuschagne, M.T.; Osthoff, G.; Hugo, A.; Bothma, C. 2005. Physical and chemical properties associated with food quality in sorghum. South African Journal of Plant and Soil 22: 175-179.

Hunter, E.; Anderson, I. 1997. Sweet sorghum. In: Janick, J., ed. Horticultural reviews, John Wiley, New York, NY, USA.

Jane, J.; Chene, Y.Y.; Lee, L.F.; McPherson, A.E.; Wong, K.S.; Radosavljevic, M.; Kasemsuwan, T. 1999. Effects of amylopectin branch chain length and amylose content on the gelatinization and pasting properties of starch. Journal of Cereal Science 76: 629-637.

Juliano, B.O.; Albano, E.L.; Cagampang, G.B. 1964. Variability in protein content, amylose content and alkali digestibility of rice varieties in Asia. The Philippine Agriculturalist 48: 234-241.

Lee, W.J.; Pedersen, J.F.; Shelton, D.R. 2002. Relationship of sorghum kernel size to physiochemical, milling, pasting, and cooking properties. Food Research International 35: 643-649.

McDonough, M.C.; Anderson, B.J.; Acosta-Zuleta, H.; Rooney, L.W. 1998. Steam flaking characteristics of sorghum hybrids and lines with differing endosperm characteristics. Cereal Chemistry 75: 634-638.

Mehmood, S.; Bashir, A.; Amad, A.; Akram, Z. 2008. Molecular characterization of regional Sorghum bicolor varieties from Pakistan. Pakistan Journal of Botany 40: 2015-2021.

Mohammadi, S.A.; Prasanna, B.M. 2003. Analysis of genetic diversity in crop plants-salient statistical tools and considerations: review and interpretation. Crop Science 43: 1235-1248.

Mudjisihino, R.; Damardjati, D.S. 1987. Prospects usefulness sorghum as a source of food and feed. Journal of Agricultural Research Development 1: 1-5.

NCSS. 2004. Number Cruncher Statistical Systems, Dr. Jerry L. Hintze, 329 North 1000 East, Kaysville, Utah 84037, Canada.

Oria, M.P.; Hamaker, B.R.; Axtell, J.D.; Huang, C.H. 2000. A high digestible mutant cultivar exhibits a unique folded structure of endosperm protein body. Proceedings of the National Academy of Science 10: 5065-5070.

Osman, M.A. 2004. Changes in sorghum enzyme inhibitors, phytic acid, tannins and in vitro protein digestibility occurring during Khamir (local) bread fermentation. Food Chemistry 88: 129-134.

Owuama, C.I. 1997. Sorghum: a cereal with large beer brewing potential. World Journal of Microbiology and Biotechnology 13: 253-260.

Perez-Maldonado, R.A.; Rodriguez, H.D. 2007. Nutritional Characteristics of 26 Sorghums in Queensland and New South Wale for Chicken Meat Production. RIRDC, Barton, Australia. (RIRDC Publication, 7).

Ragaee, S.; Abdel-Aal, E.M.; Noaman, M. 2006. Antioxidant activity and nutrient composition of selected cereals for food use. Food Chemistry 98: 32-38.

Rajvanshi, A.K.; Nimbkar, N. 2008. Sweet Sorghum Research and Development at the Nimbkar Agricultural Research Institute (NARI). Nimbkar Agricultural Research Institute, Maharashtra, India.

Ring, S.H.; Akingbala, J.O.; Rooney, L.W. 1982. Variation in amylose content among sorghums. In: Rooney, L.W.; Murty, D.S., eds. International symposium on sorghum grain quality. ICRISAT, Patencheru, India, pp. 269-279.
Sabramanian, V.; Prasada Rao, K.E.; Mengesha, M.H.; Jambunathan, R. 1987. Total sugar content in sorghum stalks and grains of selected cultivars from the world germplasm collection. Journal of the Science of Food and Agriculture 39: 289-295.

Salinas, I.; Pro, A.; Salinas, Y.; Sosa, E.; Becerril, C.M.; Cuca, M.; Cervantes, M.; Gallegos, J. 2006. Compositional variation amongst sorghum hybrids: effect of kafirin concentration on metabolizable energy. Cereal Science 44: 342-346.

Sang, Y.; Bean, S.; Seib, P.A.; Pedersen, J.; Shi, Y. 2008. Structure and functional properties of sorghum starches differing in amylose content. Journal of Agriculture and Food Chemistry 56: 6680-6685.

Shegro, A.; Labuschagn, M.T.; Shargie, N.G.; Biljon, A. van. 2013. Multivariate analysis of nutritional diversity in sorghum landrace accessions from Western Ethiopia. Journal of Biological Sciences 13: 67-74.

Taylor, J.R.N.; Dewar, J.; Taylor, J.; Ascheraden, R.F. von. 1997. Factors affecting the porridge-making quality of South African sorghums. Journal of the Science of Food and Agriculture 73: 464-470.

Wang, D.; Bean, S.; McLaren, J.; Seib, P.; Madl, R.; Tuinstra, M.; Shi, Y.; Lenz, M.; Wu, X.; Zhao, R. 2008. Grain sorghum is a viable feedstock for ethanol production. Journal of Indian Microbiology and Biotechnology 35: 313-320.

Wester, T.J.; Gramlich, S.M.; Britton, R.A.; Stock, R.A. 1992. Effect of grain sorghum hybrid on in vitro rate of starch disappearance and finishing performance of ruminants. Journal of Animal Science 70: 2866-2876.

Yano, M.; Okuno, I.; Kawakami, J.; Satoh, H.; Omura, T. 1985. High amylose mutants of rice, Oryza sativa L. Theoretical and Applied Genetics 69: 253-257.

Zobel, H. 1988. Molecules to granules: a comprehensive starch review. Starch 40: 44-50.

Appendix I - Weather data for the growing seasons.

\begin{tabular}{llcccc}
\hline $\begin{array}{l}\text { Year } \\
(2008 / 2009)\end{array}$ & Elements & $\begin{array}{c}\text { Maximum } \\
\text { temperature }\end{array}$ & $\begin{array}{c}\text { Minimum } \\
\text { temperature }\end{array}$ & $\begin{array}{c}\text { Average } \\
\text { temperature }\end{array}$ & $\begin{array}{c}\text { Total } \\
\text { rainfall }\end{array}$ \\
\cline { 3 - 5 } & & \multicolumn{3}{c}{${ }^{\circ} \mathrm{C}$} & $\mathrm{mm}$ \\
& November & 29.07 & 15.54 & 22.31 & 89.41 \\
& December & 31.17 & 17.38 & 24.28 & 73.92 \\
& January & 29.68 & 17.65 & 23.67 & 16.24 \\
& February & 27.37 & 16.24 & 21.81 & 20.83 \\
& March & 26.79 & 13.51 & 20.15 & 73.9 \\
& April & 26.11 & 9.98 & 18.05 & 41.91 \\
& May & 21.87 & 6.41 & 14.14 & 58.17 \\
& June & 19.21 & 3.95 & 11.58 & 28.96 \\
\hline Year & Total & & & & 403.34 \\
\hline 2009/2010) & November & 27.26 & 13.50 & 20.38 & 87.88 \\
& December & 30.58 & 16.31 & 23.45 & 204.98 \\
& January & 27.26 & 17.09 & 22.18 & 242.57 \\
& February & 29.16 & 16.16 & 22.66 & 86.36 \\
& March & 28.30 & 15.15 & 21.73 & 143.00 \\
& April & 24.47 & 12.16 & 18.32 & 77.47 \\
& May & 23.23 & 6.78 & 15.01 & 25.4 \\
& June & 19.94 & -0.26 & 9.84 & 0.00 \\
\hline & Total & & & & 867.66 \\
\hline
\end{tabular}

Source: ARC-GCl, Potchefstrom, South Africa (2008-2010). 